\title{
IMPLANTATION OF STREPTOCOCCUS MUTANS ON TOOTH SURFACES IN MAN
}

\begin{abstract}
Mona L. SvanberG* and W. J. Loesche
Dental Research Institute, University of Michigan, School of Dentistry, Ann Arbor, MI 48109, U.S.A

Summary-Streptomycin-resistant strains of Streptococcus mutans were implanted as adherent growth on artificial fissures (AF). A stock culture of strain E49 (serotype a) and human isolates of serotype $c$ strains were each implanted in three subjects. The AF was retained in the occlusal surface of a tooth for $80-288 \mathrm{~h}$, during which occlusal samples from the AF and salivary samples were regularly cultured, as well as AF itself when removed from the mouth. The streptomycin-resistant marker appeared stable in vitro and in vivo. Strain E49 failed to establish, as the colony-forming units (CFU) of this organism decreased with time in the AF to low or undetectable levels. At the same time, the AF became colonized by the indigenous flora including streptomycin-sensitive strains of Strep. mutans. The implanted serotype c strains of Strep. mutans seemed to establish; the CFU of these strains in the AF did not appreciably decrease with time in vivo. This suggests that serotype $c$ strains possess a unique advantage over a stock culture of a serotype a strain in their ability to implant in the human mouth using the AF model. Although the implanted Strep. mutans strains were always found in the saliva when their numbers exceeded $10^{5} \mathrm{CFU}$ in the $\mathrm{AF}$, they were rare when the level was below $10^{5}$ CFU. In samples from the AF orifice, implanted Strep. mutans was only detected on 5 of 18 occasions, when these strains were demonstrably present within the AF.
\end{abstract}

\section{INTRODUCTION}

Streptococcus mutans is a dental pathogen in animal models (Keyes, 1968) and is statistically associated with human dental decay (Krasse et al., 1968; Loesche et al., 1975); it appears to colonize the oral cavity when teeth erupt (Carlsson et al., 1970; Berkowitz, Jordan and White, 1975). Most pre-school children have detectable levels of Strep. mutans in their dental plaque (Catalanotto, Shklair and Keene, 1975) and the mouths of older children are almost universally colonized by this organism (Loesch et al., 1975). This is in contrast with adults, where the establishment of in-vitro grown strains carrying a streptomycinresistant marker is difficult to accomplish (Krasse et al., 1967; Jordan et al., 1972; Edman et al., 1975). Krasse et al. (1967) used various methods to enhance colonization, i.e. the tooth surfaces were mechanically polished, the subjects were given multiple inoculations as mouthrinses and sucrose was ingested frequently. Edman et al. (1975) used dental floss impregnated with Strep. mutans. The labelled strains gradually disappeared from the oral cavity.

Strep. mutans seems to establish preferentially in fissures (Ikeda and Sandham, 1971; Gibbons et al., 1974; Berkowitz, Jordan and White, 1975). Our aim was to implant streptomycin-resistant Strep. mutans in fissure sites using both the natural tooth and an artificial model.

\section{MATERIALS AND METHODS}

Strep. mutans strains

Stock cultures of E49 (serotype a), FA1 (serotype b), GS5 (serotype c) and LM7 (serotype e), as well as isolates of Strep. mutans strains G, T and S (sero-

* Present address: Göteborgs universitet, Odontologiska kliniken, Fack 400, 33 Göteborg 33, Sweden. type c) obtained from the dental plaque of volunteers, were serially passed on MM10 sucrose agar plates (Syed and Loesche, 1973) containing increasing levels of streptomycin, until mutants capable of growth in the presence of $1 \mathrm{mg} / \mathrm{ml}$ of streptomycin were obtained. Strain 6715 (serotype d) was already resistant to streptomycin.

\section{Implantation}

Implantation on a natural surface. Eight adults volunteered to have streptomycin-resistant strains placed on a tooth surface. Stock cultures of the serotypes were grown overnight in a 1 per cent trypticase, 0.2 per cent yeast extract broth containing either 0.5 per cent glucose or 0.5 per cent sucrose. The cultures were centrifuged and the pellet re-suspended in $1 \mathrm{ml}$ of reduced transport fluid (RTF) (Syed and Loesche, 1972) containing 1 per cent sucrose. A tuft of sterile cotton was immersed in the suspension and placed on the occlusal surface of a wiped-dry molar tooth. The tuft containing the inoculum was retained on the occlusal surface for $3 \mathrm{~h}$ by a sheet of soft occlusal wax placed over the occlusal surface and adapted to the teeth. Salivary and occlusal samples were cultured immediately after the removal of the wax and cotton tuft and again every morning for the following 7 days.

Implantation in an artificial fissure. All of the six adult subjects (subjects C, W, M, G, T and S) who participated needed a gold crown on a first molar tooth. The crown was prepared with a recess on its occlusal surface which could accept a rectangular insert. A Mylar bag resembling the natural occlusal fissure was supported in a cast gold inlay, or insert, fabricated as described by Loe, Karring and Theilade (1973) (Fig. 1). The insert containing the Mylar bag will be termed here "artificial fissure (AF)".

Overnight cultures of the stock streptomycin-resistant $\left(\mathrm{Sm}^{\mathrm{R}}\right)$ Strep. mutans strains were centrifuged and resuspended in $1 \mathrm{ml}$ of RTF. Five microlitres of this 




Fig. 1. Culturing scheme used to obtain adherent growth of streptomycin-resistant $\left(\mathrm{Sm}^{\mathrm{R}}\right)$ strains of Strep. mutans on artificial fissures.

suspension was injected into a sterile $A F$ in vitro, whereafter the AF was immediately placed in the tooth and secured with gutta-percha. In most experiments, the $\mathrm{Sm}^{\mathrm{R}}$ strain of Strep. mutans and the AF were cultured overnight in $10 \mathrm{ml}$ of trypticase-soy broth (TSB) containing 0.1 per cent sucrose for 3 consecutive days. The AF with adherent growth of Strep. mutans strains was placed in the recess on the gold crown and retained with gutta-percha (Fig. 1).

Implantation with serotype a strains of Strep mutans in the AF. An AF containing a suspension of E49 was inserted for 48-168 h on five occasions in subject W, that with adherent growth of E49 in subject $C$ for $80,90,160$ and $220 \mathrm{~h}$, in subject $W$ for 80,160 and $220 \mathrm{~h}$ and in subject $M$ for 80,220 and $240 \mathrm{~h}$.

Implantation wih serotype $c$ strains of Strep. mutans in the $A F$. Strains $\mathrm{G}, \mathrm{T}$ and $\mathrm{S}$, which were originally isolated from subjects $\mathrm{G}, \mathrm{T}$ and $\mathrm{S}$ respectively, were implanted back into the donor's mouth as adherent growth on the AF, for 168,216 and $288 \mathrm{~h}$. Strain S was also implanted in subject $W$ on 5 occasions, in subject $G$ on 3 occasions and in subject $T$ on 2 occasions for periods varying from 90 to $288 \mathrm{~h}$.

\section{Bacterial procedure}

Unstimulated saliva was collected before the insertion of the AF and at various times thereafter. Occlusal samples were obtained in vivo from the orifice of the AF with a 26-gauge needle held in a haemostat. The AF was removed from the mouth at certain timeintervals. The Mylar bag was separated from the gold inlay and the contents cultured. The samples were immediately placed in RTF and thereafter dispersed by sonification (Branson Model W 185 D. Ncw York) for $5 \mathrm{~s}$. They were then serially diluted in RTF and $0.05-\mu \mathrm{l}$ aliquots from appropriate dilutions were placed, in duplicate, on mitis-salivarius bacitracin agar (MSB) (Gold, Jordan and van Houte, 1973) and on MM10 sucrose agar (Syed and Loesche, 1973) with and without $0.2 \mathrm{mg} / \mathrm{ml}$ of streptomycin. All plates were inoculated within $30 \mathrm{~min}$ of collection of samples and were immediately placed in the anaerobic chamber and incubated at $37^{\circ} \mathrm{C}$ for $48 \mathrm{~h}$ in an atmosphere of 85 per cent $\mathrm{N}_{2}, 10$ per cent $\mathrm{H}_{2}$ and 5 per cent $\mathrm{CO}_{2}$

Colonics of Strep. mutans strains werc identified on the various media by their characteristic colony morphology, supplemented if necessary with biochemical tests (Shklair and Keene, 1974) and by examination with fluorescent antibody directed against the various Strep. mutans serotypes (Grenier, Eveland and Loesche, 1973). Total colony-forming units (CFU) counts and Strep. mutans counts were obtained from the MM10 sucrose agar. The Strep. mutans counts were also obtained from the MSB agar. The counts of $\mathrm{Sm}^{\mathrm{R}}$ strains were obtained from the MM10 sucrose streptomycin agar. All counts were converted to $\log _{10}$ for depiction in figures.

\section{RESULTS}

Implantation of various serotypes of Strep. mutans strains on a natural tooth surface

All attempts to establish the various serotypes of $\mathrm{Sm}^{\mathrm{R}}$ Strep. mutans strains on a natural tooth surface failed. The implanted strains were not detected in the saliva or on the tooth surface in any subject after one day.

Implantation of serotype a Strep. mutans in an $A F$

Strain E49 was introduced into the mouth via the $\mathrm{AF}$ in two ways. Initially, approximately $10^{5} \mathrm{CFU}$ were syringed into the $A F$ in vitro, then the $A F$ was placed in vivo. No CFU of E49 could be detected in the AF when it was removed from the mouth after $72-120 \mathrm{~h}$. At removal, the AF was colonized by $10^{6}-10^{7}$ microorganisms including streptomycin sensitive $\left(\mathrm{Sm}^{\mathrm{s}}\right)$ strains of Strep. mutans.

In the second approach, the AF was serially passed in sucrose broth with E49 so as to obtain adherent growth of the Strep. mutans strain on the AF. The $A F$, at the time of insertion into the mouth of the 3 subjects, contained an average of $10^{7}$ CFU of strain E49 (range: $1.26 \times 10^{6}-2.51 \times 10^{7} \mathrm{CFU}, n=20$ ). These AF levels decreased over a 240 -h period to undetectable or low levels in subjects $C$ and $M$ and to about $10^{5} \mathrm{CFU}$ in subject $\mathrm{W}$ (Fig. 2).

On all occasions in subjects $C$ and $W$, and on one of three occasions in subject $\mathrm{M}$, the AF became colonized by $\mathrm{Sm}^{\mathrm{s}}$ strains of Strep. mutans (Fig. 2). The numbers of these presumably endogenous organisms increased in the AF with time. On the two occasions in subject $\mathrm{M}$, that the $\mathrm{Sm}^{\S}$ strains failed to appear in the $\Lambda \mathrm{F}$ ( $\mathrm{Fig}$. 2), the average salivary concentrations were below $10^{3}$ CFU per $\mathrm{ml}$. Subject $\mathrm{M}$ during this period of low salivary Strep. mutans levels had a low sucrose intake and was not cating betwecn meals. Subsequently, salivary Strep. mutans levels in subject $M$ increased to about $1.4 \times 10^{4}$ CFUs per ml (Fig. 2) when frequent food snacks were taken. The single AF placed into his mouth during this time was readily colonized by his endogenous Strep. mutans. The average salivary concentrations of endogenous Strep. mutans in subjects $\mathrm{C}$ and $\mathrm{W}$ when the AFs were being colonized by $\mathrm{Sm}^{\mathrm{s}}$ organisms was $3.1 \times 10^{4} \mathrm{CFU}$ per $\mathrm{ml}$ in subject $\mathrm{C}$ and $5.0 \times 10^{5}$ in subject $\mathrm{W}$ (Table 1).

The implanted strain E49 was shed from the AFs into the saliva (Fig. 2). The salivary levels of strain E49 in subjects $C$ and $M$ decreased with time from about $10^{5}$ CFUs immediately after insertion of the $\mathrm{AF}$ to undetectable levels, i.e. less than $10^{\mathrm{t}} \mathrm{CFUs}$ per $\mathrm{ml}$, within $85-160 \mathrm{~h}$ (Figs. 2a and $2 \mathrm{c}$ ). In subject $\mathrm{W}$, the salivary concentration of strain E49 also de- 

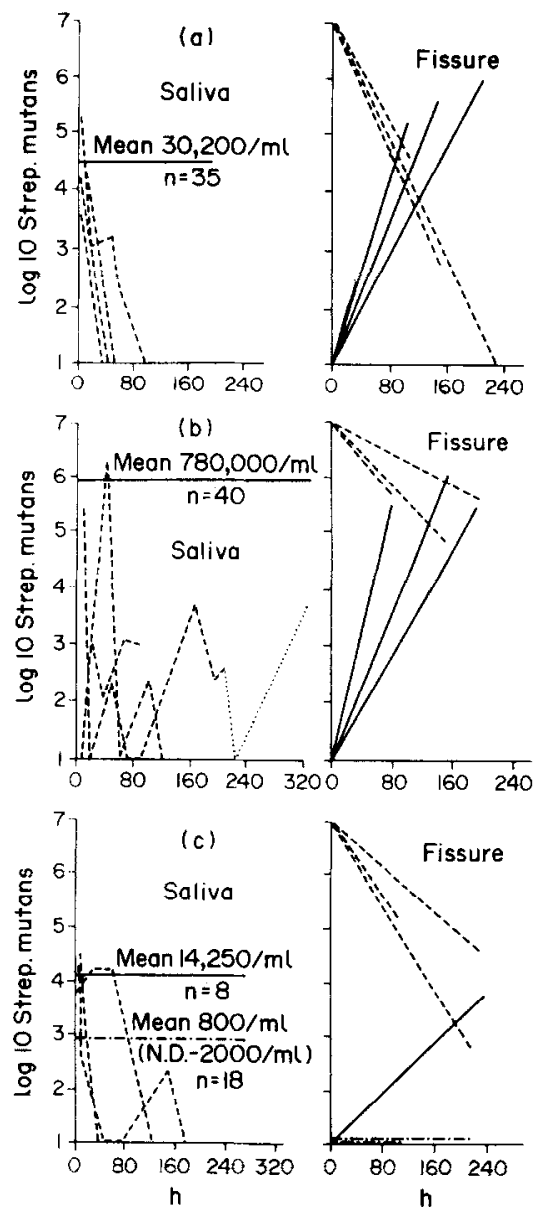

Fig. 2. Concentration $(\log 10)$ of streptomycin-resistant strain E49 and streptomycin-sensitive strains of Strep. mutans in the salivas and in the artificial fissures of three subjects: subject $C(a)$; subject W(b); subject $M(c)$. Symbols used: solid line represents values for streptomycin-sensitive Strep. mutans in the saliva and AF; broken line represents values for streptomycin-resistant strain E49 in saliva and AF; dotted line represents salivary concentrations of strain E49 after removal of the AF; dash-dot-dash line represents streptomycin-sensitive Strep. mutans in the saliva of subject $M(c)$ during a period when the AF did not become colonized by this organism.

creased, but showed an oscillating pattern between $10^{1}$ to $10^{4}$ CFUs per $\mathrm{ml}$ and, on one occasion, was detected $114 \mathrm{~h}$ after the removal of the AF (Fig. 2b).

The disappearance of strain E49 from the AF and saliva was coincident with the increase of $\mathrm{Sm}^{\mathrm{s}}$ strains of Strep. mutans in the AF (Fig. 2), suggesting that strain E49 may have back-mutated and lost its $\mathrm{Sm}^{\mathrm{R}}$ marker in vivo. This possibility was ruled out by examination of the number of CFUs of Strep. mutans which grew on the MSB, MM10 sucrose agar with streptomycin and MM10 sucrose agar without streptomycin. Strain E49; like all serotype a strains of Strep. mutans, is bacitracin sensitive and therefore does not grow on MSB agar (Shklair and Keene, 1974). Endogenous strains of Strep. mutans are primarily of serotypes c, d and e (Bratthall, 1972; Thomson, Little and Hageage. 1976; Loesche and Grenier, 1976) and will grow on MSB agar (Shklair and Keene. 1974). E49 can therefore be distinguished from any E49 $\mathrm{Sm}^{\mathrm{s}}$ mutants and from endogenous strains of Strep. mutans (Table 2). The $\mathrm{Sm}^{\mathrm{s}}$ Strep. mutans strains that displaced strain E49 in the AF grew on MSB agar and were therefore presumably of endogenous origin, i.e. the streptomycin-resistant marker appeared to be stable in vitro and in vivo.

Implantation of serotype c strains of Strep. mutans in an $A F$

Subjects $G, T$ and $S$ were inoculated with an $A F$ containing adherent growth of $\mathrm{Sm}^{\mathrm{R}}$ strains $\mathrm{G}, \mathrm{T}$ and $\mathrm{S}$ of Strep. mutans, originally isolated from the subject's own mouth. All AFs had detectable levels of $\mathrm{Sm}^{\mathrm{R}}$ strains at their removal from the mouth (Fig. 3). In subject $G$ on one occasion (Fig. 3a), in subject $\mathrm{T}$ on 2 occasions (Fig. 3b) and in subject $\mathrm{S}$ on 3 occasions (Fig. 3c), the final levels of the $\mathrm{Sm}^{\mathrm{R}}$ strains of Strep. mutans in the AF were essentially the same as the starting levels.

In subjects $G$ and $T$, all AFs were at the time of removal also colonized by $\mathrm{Sm}^{\mathrm{S}}$ strains of Strep. mutans (Figs. 3a and b). In subject $S$, on no occasion could any $\mathrm{Sm}^{\mathrm{s}}$ Strep. mutans strains be detected (Fig. 3c). The average salivary concentrations of these endogenous $\mathrm{Sm}^{\mathrm{s}}$ strains of Strep. mutans were approximately $3.7 \times 10^{3}$ CFUs per $\mathrm{ml}$ in subject $\mathrm{G}$. $1.6 \times 10^{4}$ in subject $\mathrm{T}$ and $1.4 \times 10^{6}$ in subject $\mathrm{S}$ (Table 1, Fig. 3).

The implanted strains $G, T$ and $S$ shed from the AFs into the saliva. Their salivary concentrations varicd from about $10^{5}$ CFUs per $\mathrm{ml}$ immediately after implantation to about $10^{1}-10^{3}$ CFUs at the time of removal of the AF from the mouth. In one experiment in each subject, the saliva was repeatedly cultured for the $\mathrm{Sm}^{\mathrm{R}}$ strains after the AF was withdrawn from

Table 1. Salivary concentrations of streptomycin-sensitive Strep. mutans

\begin{tabular}{cccc}
\hline & $\begin{array}{c}\text { Strep. mutans } \\
\text { CFU/ml } \\
\text { average }\end{array}$ & Range & $\begin{array}{c}\text { No. of } \\
\text { samples }\end{array}$ \\
\hline Subject & $3.16 \times 10^{4}$ & $2.0 \times 10^{3}-1.6 \times 10^{5}$ & 35 \\
$\mathrm{C}$ & $7.8 \times 10^{5}$ & $3.1 \times 10^{4}-1.0 \times 10^{7}$ & 40 \\
$\mathrm{~W}$ & $8.0 \times 10^{2}$ & $<10^{2}-2.0 \times 10^{3}$ & 18 \\
$\mathrm{M}$ & $1.4 \times 10^{4}$ & $10^{2}-3.2 \times 10^{4}$ & 8 \\
$\mathrm{G}$ & $3.7 \times 10^{3}$ & $<10^{2}-2.0 \times 10^{4}$ & 45 \\
$\mathrm{~T}$ & $1.6 \times 10^{4}$ & $7.9 \times 10^{3}-4.0 \times 10^{4}$ & 31 \\
$\mathrm{~S}$ & $1.4 \times 10^{6}$ & $6.3 \times 10^{4}-6.3 \times 10^{7}$ & 50 \\
\hline
\end{tabular}


Table 2. Antibiotic-resistance scheme to determine whether streptomycin resistant serotype a strains of Strep. mutans lose this marker in vivo

\begin{tabular}{lccc}
\hline & MSB agar & $\begin{array}{c}\text { With } \\
\text { streptomycin }\end{array}$ & $\begin{array}{c}\text { Without } \\
\text { streptomycin }\end{array}$ \\
Growth on & - & + & + \\
\hline E49 Sm & - & - & + \\
E49 Sm & + & - & + \\
Endogenous Strep. mutans & + & + & + \\
Strains & + & + & \\
G, T and S & + & &
\end{tabular}

the mouth. In each instance, the salivary levels decreased to barely detectable values or were undetectable (Fig. 3).

The AF-containing adherent growth of strain $\mathrm{S}$ did not become colonized by endogenous Strep. mutans, even though subject $\mathrm{S}$ had the highest salivary Strep. mutans level (Table 1). This absence of colonization could reflect some inhibitory attribute of strain $\mathrm{S}$ or
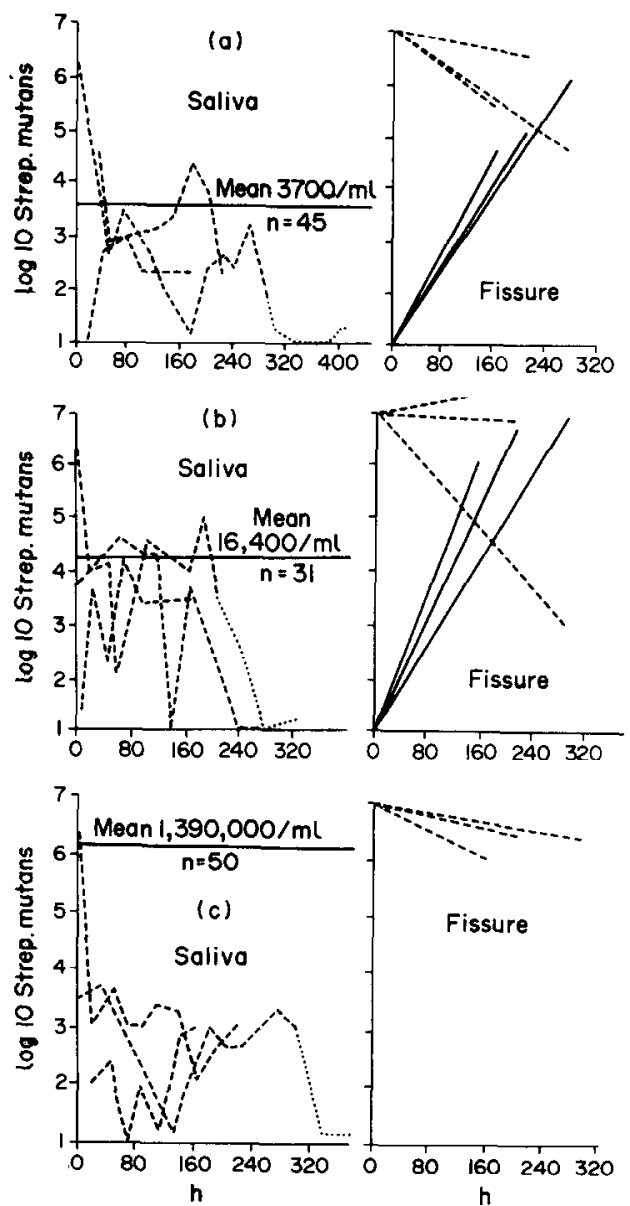

Fig. 3. Concentrations of streptomycin-resistant strains, i.e. strain $G$ in subject $G(a)$, strain $T$ in subject $T(h)$ and strain $S$ in subject $S(c)$, in the saliva and in the $A F$ of three subjects. Symbols used: solid line represents values for streptomycin-sensitive Strep. mutans in saliva and AF; dashed line represents values for $\mathrm{Sm}^{\mathrm{R}}$ Strep. mutans in saliva and $\mathrm{AF}$; dotted line represents salivary concentrations of $\mathrm{Sm}^{\mathrm{R}}$ Strep. mutans after removal of the AF. could be due to the inability in subject $S$ of endogenous Strep. mutans to colonize the AF. In additional experiments, subjects $G, T$ and $W$ were inoculated with strain $S$ as adherent growth in the AF. When the AFs were removed after $90-288 \mathrm{~h}$ in vivo, they contained about $10^{4}-10^{7} \mathrm{CFUs}$ of strain S. As in subject $\mathrm{S}$, no $\mathrm{Sm}^{\mathrm{S}}$ Strep. mutans could be detected among the indigenous microorganisms that had colonized the AF.

Relationship between the salivary and $A F$ concentrations of the implanted serotype $c$ strains of Strep. mutans

Saliva samples were always collected from subjects $\mathrm{G}, \mathrm{T}$, and $\mathrm{S}$ immediately before the removal and culturing of the AF from the tooth. When the data from the 3 subjects were combined, a relationship between the levels of $\mathrm{Sm}^{\mathrm{R}}$ strains in the $\mathrm{AF}$ and in the saliva was detected. When the total number of the $\mathrm{Sm}^{R}$ Strep. mutans strains was below $10^{5}$ CFUs in the AF (Fig. 4), these strains were detected in only 1 of 9 salivary samples. However, when the number of $\mathrm{Sm}^{\mathrm{R}}$ Strep. mutans in the AF exceeded $10^{5}$ CFUs, they were always found in the salivary samples, but its numbers per $\mathrm{ml}$ were 2.5-4 log lower than its total number in the AF.

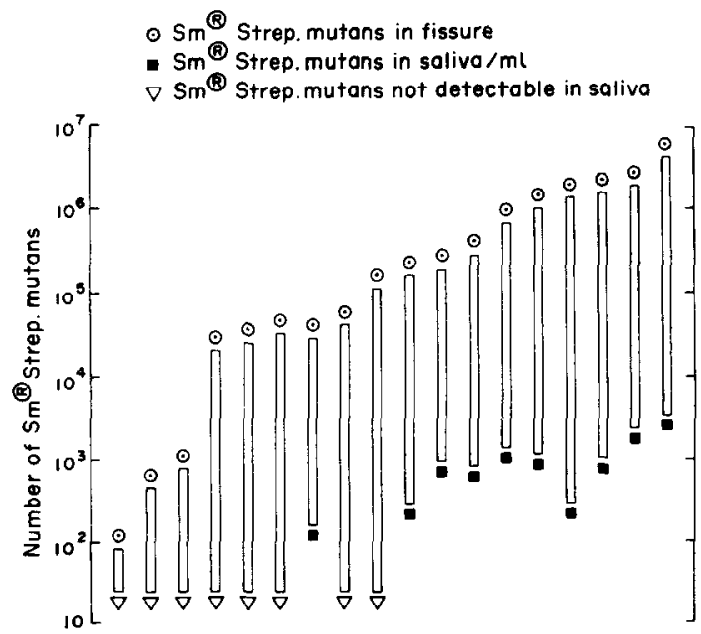

Fig. 4. The relationship between AF levels of streptomycin-resistant $\left(\mathrm{Sm}^{\mathbf{R}}\right)$ Strep. mutans and the salivary levels of these organisms. Note that when the fissure levels were $\geq 10^{5}$ CFUs the $\mathrm{Sm}^{\mathrm{R}}$ strains were always detectable in the saliva. 
Relationship between samples positive for the implanted serotype $c$ strains of Strep. mutans from the orifice of the $A F$ and from the total $A F$

The orifice of the AF was sampled immediately before the removal of the AF. Streptomycin-resistant Strep. mutans strains were detected on only 5 out of 18 occasions when these strains were demonstrably present in the AF.

\section{DISCUSSION}

Our findings confirm and extend previous investigations concerning the difficulty of implanting in-vitro grown, streptomycin-resistant strains of Strep. mutans in the mouths of adults (Krasse et al., 1967; Jordan et al., 1972). All attempts to establish the various serotypes by implantation on a natural tooth surface failed. Failure to detect the $\mathrm{Sm}^{\mathrm{R}}$ strain could mean that either it was rapidly cleared from the mouth, or that it had back-mutated and lost its streptomycinresistant marker. The $\mathrm{Sm}^{\mathrm{S}}$ strains of Strep. mutans which colonized the AFs were all resistant to bacitracin, indicating that they were not mutants of strain E49, unless an extremely rare double mutation had occurred. It was more likely, therefore, that the endogenous strains of Strep. mutans were able to compete extremely well in the AF, whereas strain E49, given an initial advantage, could not.

Strain E49 persisted in only one subject (Fig. 2b). Serotype c human isolates of Strep. mutans isolated from the subjects' own mouths, however, was established in all cases (Fig. 3). In 6 out of 9 experiments, the total CFU of the implanted strains $G, T$ and $S$ in the AF at the time of removal from the mouth was approximately the same as when the AF was introduced. Strain $S$ was successfully implanted in 4 individuals. This would suggest that serotype $\mathrm{c}$ strains possess a unique advantage over serotype a strain E49 in their ability to implant in the human mouth using the AF model. This agrees with the relative absence of serotype a strains of Strep. mutans and the predominance of serotype $c$ strains in man (Bratthall, 1972; Thomson et al., 1976; Loesche and Grenier, 1976). Strain E49 was originally isolated from hamster teeth (Fitzgerald and Keyes, 1960). Krasse et al. (1967) found a higher clearance from the human mouth of the serotype a, hamster Strep. mutans strain 3720 than that of the human serotype c Strep. mutans strain Ingbritt. This suggests that man possesses salivary factors directed against serotype a and/or that serotype c strains possess some attribute(s), possibly a surface receptor, that gives them an ecological advantage over serotype a strains when both are introduced into the mouth. Strain E49 has been maintained by laboratory transfer for 15 years, possibly resulting in changes which could be of some significance for the ecological differences observed between the serotype $a$ and the recently-isolated serotype $c$ strains (Gibbons and Fitzgerald, 1969; Ellwood et al., 1976). These changes could be tested for by studies using recent human isolates of serotype a and old stock cultures of a serotype $c$ strain. Also, within the serotype c, Strep. mutans strains differences may exist that influence establishment. When strains $G$ and $T$ were introduced as in-vitro cultured adherent growth in the
AF, streptomycin-sensitive strains of Strep. mutans readily colonized the $\mathrm{AF}$ in numbers increasing with time. When strain $S$ was implanted using the same technique in 4 separate individuals, no $\mathrm{Sm}^{\mathrm{s}}$ Strep. mutans colonized the AF, indicating that some characteristic of strain $S$ inhibited the colonization.

Svanberg and Loesche (1977) showed that the AFs become colonized by endogenous Strep. mutans at salivary levels of $\geq 10^{3}$ CFUs per $\mathrm{ml}$. We found that, with the exception of the AFs containing strain $S$, all AFs became colonized by endogenous Strep. mutans whenever this organism was $\geq 10^{3}$ CFUs per $\mathrm{ml}$ of saliva. In subject $\mathbf{M}$, when his saliva contained a mean of 800 CFUs of Strep. mutans per $\mathrm{ml}$, the AFs did not become colonized with this organism.

The bacteriological results of samples from the saliva and AF orifice, which were collected immediately before the removal of the AF, show the difficulty in detecting absolutely a Strep. mutans infection in a retention site such as a fissure. When more than $10^{5} \mathrm{Sm}^{\mathrm{R}} \mathrm{CFU}$ of Strep. mutans were present in the $A F$, they were always detectable in the saliva. When the AF contained less than $10^{5} \mathrm{Sm}^{\mathrm{R}} \mathrm{CFU}$ of Strep. mutans, only 1 out of 9 salivary samples was positive for these microorganisms. In samples taken from the orifice of the AF, the $\mathrm{Sm}^{\mathrm{R}}$ strains of Strep. mutans were undetected in 13 out of 18 occasions in which these strains were demonstrably present in the contents of the AF. These findings illustrate one reason why tests based upon detection of Strep. mutans strains have only a relative predictive value as an indicator of preclinical caries (Svenson, Liljemark and Schuman, 1976).

Acknowledgements-This work was supported by U.S. Public Health Grants Nos. DE-02731, DE-03011 and DE-03423 from the National Institute of Dental Research. Dr. Thorkild Karring generously provided some of the AFs and Dr. Harry Pape prepared the gold crowns.

\section{REFERENCES}

Berkowitz R. J., Jordan H. V. and White G. 1975. The early establishment of Streptococcus mutans in the mouths of infants. Archs oral Biol. 20, 171-174

Bratthall D. 1972. Demonstration of Streptococcus mutans strains in some selected areas of the world. Odont. Revy 23, 401-410.

Carlsson J., Grahnen H., Jonsson G. and Wikner S. 1970 Establishment of Streptococcus sanguis in the mouths of infants. Archs oral Biol. 15, 1143-1148.

Catalanotto F. A., Shklair I. L. and Keene H. J. 1975. Prevalence and localization of Streptococcus mutans in infants and children. J. Am. dent. Ass. 91, 606-609.

Edman D. C., Keene H. J., Shklair I. L. and Hoerman K. C. 1975. Dental floss for implantation and sampling of Streptococcus mutans from approximal surfaces of human teeth. Archs oral Biol. 20, 145-148.

Ellwood D. C., Baird J. K., Hunter J. T. and Longyear V. M. 1976. Variations in surface polymers of Streptococcus mutans. J. dent. Res. 55, (special issue C) $42-49$.

Fitzgerald R. J. and Keyes P. H. 1960. Demonstration of the etiologic role of streptococci in experimental caries in the hamster. J. Am. dent. Ass. 61, 9-19.

Gibbons R. J. and Fitzgerald R. J. 1969. Dextran-induced agglutination of Streptococcus mutans and its potential role in the formation of microbial dental plaques. $J$. Bact. 98, 341-346. 
Gibbons R. J., de Paola P. F., Spinell D. M. and Skobe Z. 1974. Interdental localization of Streptococcus mutans as related to caries experience. Infect. Immun. 9, 481488.

Gold O. G., Jordan H. V. and van Houte J. 1973. A selective medium for Streptococcus mutans. Archs oral Biol. 18, 1357-1364.

Grenier E. M., Eveland W. C. and Loesche W. J. 1973. Identification of Streptococcus mutans serotypes in dental plaque by fluorescent antibody techniques. Archs oral Biol. 18, 707-715.

Ikeda T. and Sandham H. J. 1971. Prevalence of Streptococcus mutans on various tooth surfaces in Negro children. Archs oral Biol. 16, 1237-1240.

Jordan H. V., Englander H. R., Engler W. O. and Kulczyk S. 1972. Observations on the implantation and transmission of Streptococcus mutans in humans. J. dent. Res. i1, 515-518.

Keyes P. H. 1968. Research in dental caries. J. Am. dent. Ass. 76, 1357-1373.

Krasse B., Edwardsson S., Svensson I. and Trell L. 1967. Implantation of caries inducing streptococci in the human oral cavity. Archs oral Biol. 12, 231-236.

Krasse B., Jordan H. V., Edwardsson S., Svensson I. and Trell L. 1968. The occurrence of certain "caries-inducing" streptococci in human plaque material. Archs oral Biol. 13, 911-918.

Loe H., Karring T. and Theilade E. 1973. An in-vivo method for the study of the microbiology of occlusal fissures. Caries Res. 7, 120-129.
Loesche W. J. and Grenier E. M. 1976. Detection of Streptococcus mutans in plaque samples by the direct fluorescent antibody test. J. dent. Res. 55, (special issue A), 87-93.

Loesche W. J., Rowan J., Straffon L. H. and Loos P. J. 1975. Association of Streptococcus mutans with human dental decay. Infect. Immun. 11, 1252-1260.

Shklair I. L. and Keene H. J. 1974. A biochemical scheme for the separation of the five varieties of Streptococcus mutans. Archs oral Biol. 19, 1079-1081.

Swenson J. I., Liljemark W. F. and Schuman L. M. 1976. A longitudinal epidemiologic evaluation of the association between the detection of plaque streptococci and development of dental caries in children. Microbiological Aspects of Dental Caries (Edited by Stiles, Loesche and O'Brien). Sp. Supp. Microbiology. 1, 211-222.

Syed S. A. and Loesche W. J. 1972. Survival of human dental plaque flora in various transport media. Appl. Microbiol. 24, 638-644.

Syed S. A. and Loesche W. J. 1973. Efficiency of various growth media in recovering oral bacterial flora from human dental plaque. Appl. Microbiol. 26, 459-465.

Svanberg M. L. and Loesche W. J. 1977. Salivary concentration of Streptococcus mutans and Streptococcus sanguis and the colonization of artificial fissures in man. Archs oral Biol. 22, 441-447.

Thomson L. A., Little W. and Hageage G. J. 1976. Application of fluorescent antibody methods in the analysis of plaque samples. $J$. dent. Res. Special issue A, 55, A80-A87. 